\title{
Comparison of haemodynamic effects of oral hydralazine and prazosin hydrochloride in patients with chronic congestive heart failure ${ }^{1}$
}

\author{
KANU CHATTERJEE, THOMAS A. PORTS, STEPHEN ARNOLD, \\ BRUCE BRUNDAGE, AND WILLIAM PARMLEY
}

\begin{abstract}
From the Cardiovascular Research Institute and the Cardiovascular Division of the Department of Medicine, University of California, San Francisco, California, USA
\end{abstract}

SUMMARY The comparative haemodynamic effects of oral prazosin hydrochloride and hydralazine were evaluated in 11 patients with chronic congestive heart failure.

The maximum total dose of prazosin received by an individual varied up to $25 \mathrm{mg}$. Ten patients received a maximum of $75 \mathrm{mg}$ and one received $50 \mathrm{mg}$ of hydralazine at six-hour intervals. There was no significant change in heart rate with either drug. Decrease in mean arterial and left ventricular filling pressures were modest and similar with both agents. With prazosin, the average cardiac index increased 20 per cent and systemic vascular resistance decreased 20 per cent. By contrast, hydralazine increased cardiac index by 58 per cent and decreased systemic vascular resistance by 40 per cent. The increase in stroke work and stroke volume indices was significantly greater with hydralazine than with prazosin.

These findings suggest that in some patients with severe chronic congestive heart failure, improvement in left ventricular performance may be greater with hydralazine than with prazosin.

Vasodilator therapy is effective in some patients with chronic heart failure. Intravenous vasodilators can improve the haemodynamic and clinical status of patients in hospital with severe heart failure (Majid et al., 1971; Guiha et al., 1974; Chatterjee et al., 1976a; Kovick et al., 1976; Chatterjee and Parmley, 1977). Several nonparenteral vasodilators have also been investigated for long-term use in patients with chronic heart failure (Gold et al., 1972; Franciosa et al., 1974b; Gray et al., 1975; Chatterjee et al., 1976b; Kovick et al., 1976; Mantle et al., 1976; Taylor et al., 1976). With accumulated experience, it is apparent that though most vasodilators produce qualitatively similar haemodynamic effects, the magnitude of the responses may differ significantly. Recently, the haemodynamic effects of two vasodilators, hydralazine and prazosin, have been investigated in different groups of patients with chronic congestive heart failure and beneficial responses to both drugs have been reported (Chatterjee et al., 1976b; Franciosa et al., 1977; Miller et al., 1977; Awan et al., 1977).

1This work was supported in part by a NHLBI Program Project grant.

Received for publication 26 February 1979
However, no information about the comparative haemodynamic effects of these drugs in the same group of patients is available. The purpose of this study was to compare the haemodynamic effects of oral hydralazine and prazosin in the same patients with severe chronic congestive heart failure.

\section{Methods}

\section{PATIENTS}

The comparative effects of prazosin and hydralazine were investigated in 11 patients with chronic congestive heart failure. There were seven women and four men with an age range of 27 to 76 years. The aetiology of heart failure was ischaemic heart disease in seven patients, and cardiomyopathy of unknown cause in the other four. In two patients, there was a history of hypertension, though no patient was hypertensive at the time of the study. One patient had significant mitral regurgitation on the ventriculogram, in addition to poor left ventricular function, but in the other patients there was no clinical evidence of significant mitral regurgitation. All patients had clinical and radiological evidence of cardiomegaly, poor left ventricular function, 
pulmonary hypertension, and signs and symptoms of systemic and pulmonary venous congestion. Seven patients were in class IV of the New York Heart Association classification, four in class III.

The duration of heart failure ranged from seven months to five years. All patients were being treated with digitalis and diuretics. Serum digoxin levels at the time of the study ranged from 1.0 to 3.7 $\mathrm{nmol} / 1(0.8$ to $2.9 \mathrm{ng} / \mathrm{ml})$. The diuretic and digoxin were continued throughout the study period. Three patients were in atrial fibrillation with a controlled ventricular response, while the remaining eight patients were in sinus rhythm at the time of the study.

\section{HAEMODYNAMIC MEASUREMENTS}

Pulmonary artery (PAP), pulmonary artery wedge (PAW), and right atrial (RAP) pressures were measured with the use of a triple lumen, balloon-tip flotation catheter (Forrester et al., 1972). Pulmonary artery diastolic pressure was used as a measure of left ventricular filling pressure in one patient in whom a wedge pressure record could not be obtained. Mid-chest level was used as the reference point of the measurement of intracardiac pressures. Cardiac outputs were determined in triplicate by the thermodilution technique (Forrester $e t$ al., 1972). The variability of triplicate cardiac output measurements was less than 10 per cent. Arterial mean pressure was measured by inserting a 20 gauge arterial cannula into the radial artery. In three patients with atrial fibrillation, arterial pressure was determined by averaging several consecutive beats. Derived haemodynamic indices were calculated as follows:

Cardiac index (CI) $\left(1 / \mathrm{min}\right.$ per $\left.\mathrm{m}^{2}\right)=$ cardiac output/body surface area;

Stroke volume index (SVI) $\left(\mathrm{ml}\right.$ per $\left.\mathrm{m}^{2}\right)=$ $\mathrm{CI} /$ heart rate;

Stroke work index (SWI) $\left(\mathrm{g} \mathrm{m}\right.$ per $\left.\mathrm{m}^{2}\right)=(\mathrm{LV}$ mean systolic-PAW mean pressure) $\times$ SVI $\times$ 0.0136;

Systemic arterial mean pressure (MAP) $(\mathrm{mmHg})$

$=$ diastolic pressure $+\frac{\text { systolic-diastolic }}{3}$;

Systemic vascular resistance (SVR) (dynes $\mathrm{sm}^{-5}$ )

$$
=\frac{\text { MAP }- \text { mean RA pressure }}{\text { cardiac output }} \times 80 \text {; }
$$

Pulmonary vascular resistance (PVR) (dynes $s$ $\mathrm{cm}^{-5}$ )

$$
=\frac{\text { PA mean }- \text { PAW mean pressure }}{\text { cardiac output }} \times 80
$$

\section{DRUG ADMINISTRATION}

After initial control haemodynamic measurements had been made, prazosin was administered first in eight patients, followed by oral hydralazine. In three patients, oral hydralazine was administered first, and then oral prazosin.

The initial oral dose of prazosin was 40 to $50 \mu \mathrm{g}$ per $\mathrm{kg}(2 \mathrm{mg}$ in four patients and $3 \mathrm{mg}$ in seven patients), comparable with the dose selected by previous investigators (Awan et al., 1977). Haemodynamic measurements were repeated hourly. Prazosin was then given in doses increasing by $1 \mathrm{mg}$ at three-hour intervals, until a $5 \mathrm{mg}$ dose was administered. Nine patients received two additional $5 \mathrm{mg}$ doses at eight hour intervals.

The initial oral dose of hydralazine was $50 \mathrm{mg}$ which was increased six hours later to $75 \mathrm{mg}$ in 10 of 11 patients; in one patient there was a large increase in cardiac output with $50 \mathrm{mg}$ hydralazine, and the dose was not increased. Haemodynamic measurements were repeated hourly. Oral hydralazine was then given at six-hour intervals up to 36 hours, with frequent haemodynamic measurements.

After determination of the haemodynamic response to the first drug administered (prazosin or hydralazine), the haemodynamic variables were allowed to return to control levels over 12 to 24 hours. Haemodynamic measurements were repeated to ensure return to control levels before the administration of the second drug; those obtained before administration of this drug served as control. Haemodynamic measurements made at the time of maximum effect of the drug on cardiac index were recorded at each dose level for both drugs and compared.

Statistical analyses of the data used a two-way analysis of variance, without replication and a mixed effects model. Data were expressed as the mean \pm standard error of the mean (SEM).

\section{Results}

The control haemodynamic data before the administration of prazosin (C1) or hydralazine (C2), irrespective of the order of their administration, were remarkably similar (Table). The average cardiac index was almost the same and there were only minor differences in other haemodynamic measurements, none of which were statistically significant.

\section{HAEMODYNAMIC EFFECTS OF ORAL}

PRAZOSIN

The maximum haemodynamic response was defined in terms of increase in cardiac output and was usually observed one to two hours after the first 
Table Haemodynamic effects (mean $\pm S E M$ ) of oral prazosin and hydralazine in patients with chronic congestive heart failure

\begin{tabular}{|c|c|c|c|c|c|c|c|c|c|c|}
\hline & $\begin{array}{l}H R \\
\text { (beats) } \\
\text { min) }\end{array}$ & $\begin{array}{l}M A P \\
(m m H g)\end{array}$ & $\begin{array}{l}M P A P \\
(m m H g)\end{array}$ & $\begin{array}{l}L V F P \\
(m m H g)\end{array}$ & $\begin{array}{l}R A P \\
(m m H g)\end{array}$ & $\begin{array}{l}C I \\
(l / \min \\
\left.\text { per } m^{2}\right)\end{array}$ & $\begin{array}{l}S V I \\
(m l \text { per } \\
\left.m^{2}\right)\end{array}$ & $\begin{array}{l}S W I \\
(g m \text { per } \\
\left.m^{2}\right)\end{array}$ & $\begin{array}{l}S V R \\
\text { (dynes } \\
s \mathrm{~cm}^{-5} \text { ) }\end{array}$ & $\begin{array}{l}\text { PVR } \\
\text { (dynes } \\
s \mathrm{~cm}^{-5} \text { ) }\end{array}$ \\
\hline $\begin{array}{l}C(1) \\
\text { P } 3 \mathrm{mg} \\
\text { P } 4 \mathrm{mg} \\
\text { P } 5 \mathrm{mg} \\
C(2) \\
\text { HD } 50 \mathrm{mg} \\
\text { HD } 75 \mathrm{mg}\end{array}$ & $\begin{array}{l}86 \pm 7 \\
83 \pm 4 \\
85 \pm 5 \\
79 \pm 3 \\
87 \pm 7 \\
86 \pm 7 \\
89 \pm 6\end{array}$ & $\begin{array}{l}87 \pm 3 \\
80 \pm 2 \\
84 \pm 3 \\
79 \pm 3 \\
87 \pm 3 \\
82 \pm 3 \\
79 \pm 2\end{array}$ & $\begin{array}{l}36 \pm 2 \\
28 \pm 2 \\
28 \pm 2 \\
28 \pm 3 \\
35 \pm 2 \\
30 \pm 3 \\
30 \pm 2\end{array}$ & $\begin{array}{l}24 \pm 1 \\
19 \pm 2 \\
19 \pm 2 \\
19 \pm 2 \\
24 \pm 1 \\
21 \pm 2 \\
20 \pm 2\end{array}$ & $\begin{aligned} 12 & \pm 1 \\
10 & \pm 2 \\
10 & \pm 1 \\
8 & \pm 1 \\
12 & \pm 1 \\
11 & \pm 1 \\
11 & \pm 2\end{aligned}$ & $\begin{array}{l}2 \cdot 0 \pm 0.1 \\
2 \cdot 5 \pm 0.2 \\
2 \cdot 4 \pm 0.2 \\
2.5 \pm 0.2 \\
2 \cdot 0 \pm 0.1 \\
2.5 \pm 0.1 \\
3.3 \pm 0.2\end{array}$ & $\begin{array}{l}26 \pm 2 \\
31 \pm 2 \\
29 \pm 2 \\
30 \pm 3 \\
25 \pm 2 \\
32 \pm 3 \\
38 \pm 3\end{array}$ & $\begin{array}{l}22 \pm 3 \\
26 \pm 3 \\
25 \pm 3 \\
25 \pm 3 \\
22 \pm 2 \\
27 \pm 3 \\
30 \pm 2\end{array}$ & $\begin{array}{l}1776 \pm 85 \\
1373 \pm 82 \\
1631 \pm 167 \\
1410 \pm 118 \\
1760 \pm 86 \\
1400 \pm 111 \\
1045 \pm 60\end{array}$ & $\begin{array}{l}285 \pm 40 \\
194 \pm 41 \\
222 \pm 31 \\
186 \pm 29 \\
270 \pm 45 \\
214 \pm 31 \\
203 \pm 25\end{array}$ \\
\hline $\begin{array}{l}\text { HD } 75 \mathrm{mg} \text { vs } P 5 \mathrm{mg} \\
C(1) \text { vs } P 5 \mathrm{mg} \\
\text { P3 vs } 4 \mathrm{mg} \text { vs } 5 \mathrm{mg} \\
C(2) \text { vs } \mathrm{HD} 50 \mathrm{mg} \\
\text { HD } 50 \mathrm{mg} \text { vs } 75 \mathrm{mg}\end{array}$ & $\begin{array}{l}- \\
- \\
-\end{array}$ & $\begin{array}{l}- \\
\star \\
\star \star \star \\
\star \star\end{array}$ & $\frac{t}{\star \star}$ & $\begin{array}{l}\overline{\star \star} \\
\overline{-} \\
-\end{array}$ & $\begin{array}{l}\star \\
\star \star \\
- \\
-\end{array}$ & $\begin{array}{l}\ddagger \\
\ddagger \\
\frac{\ddagger}{t} \\
t\end{array}$ & $\begin{array}{l}\ddagger \\
\star \star \\
- \\
\star \star \star \\
\star \star \star\end{array}$ & $\frac{\star}{-}$ & $\begin{array}{l}\dagger \\
\star \star \star \\
- \\
\ddagger \\
\ddagger\end{array}$ & $\begin{array}{l}\bar{\star} \\
\overline{-} \\
-\end{array}$ \\
\hline
\end{tabular}

$\star \mathrm{P}<0.05 ; \star \star \mathrm{P}<0.025 ; \star \star \star \mathrm{P}<0.01 ;+\mathrm{P}<0.005 ; \ddagger \mathrm{P}<0.001$.

$\mathrm{C}(1)$ : control before prazosin; C(2): control before hydralazine; CI: cardiac index; HD: hydralazine; HR: heart rate; LVFP: left ventricular filling pressure; MAP: systemic arterial mean pressure; MPAP: pulmonary artery mean pressure; $P$ : prazosin;

PVR: pulmonary vascular resistance; RAP: right atrial pressure; SVI: stroke volume index; SWI: stroke work index; SVR: systemic vascular resistance.
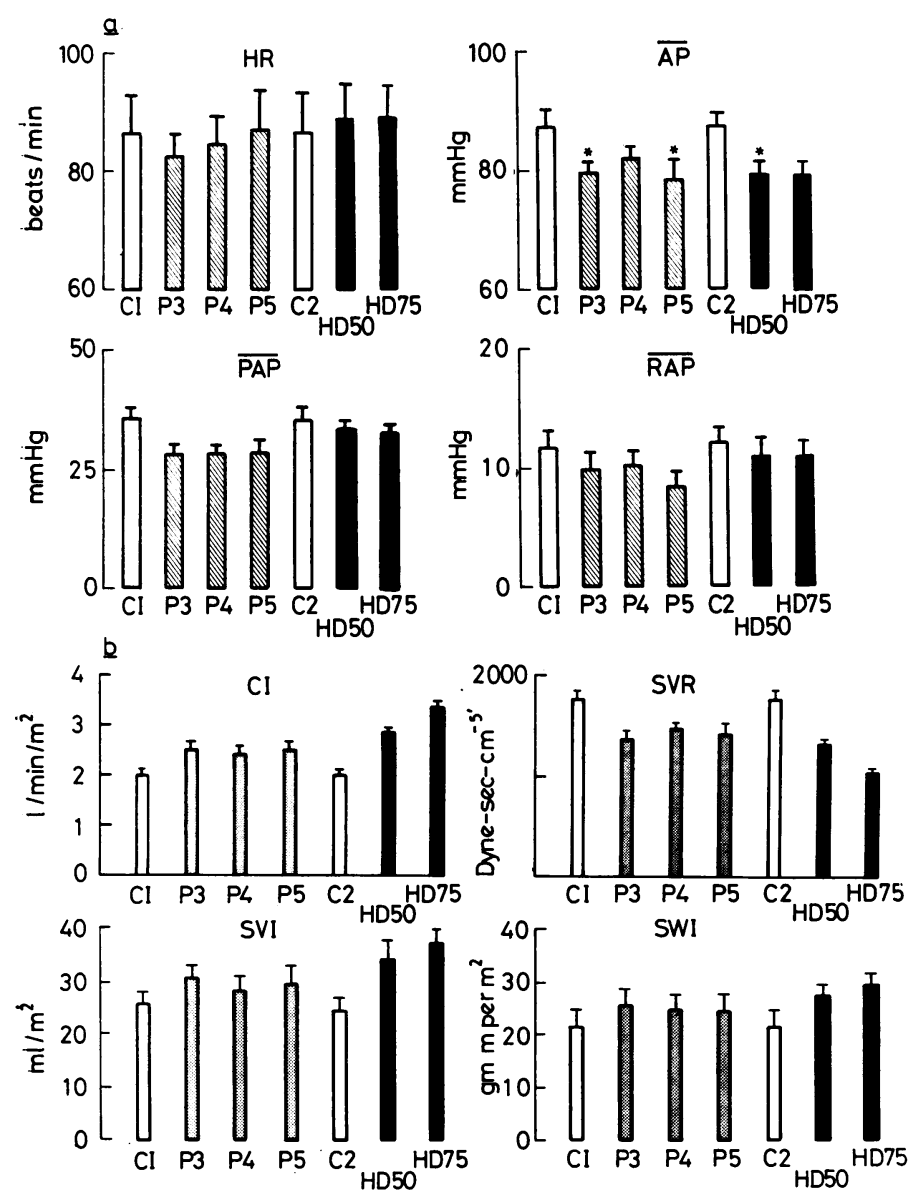

Fig. 1 Effects of oral prazosin $(3,4$, and $5 \mathrm{mg}$ ) and oral hydralazine ( 50 and $75 \mathrm{mg}$ ) on heart rate $(H R)$, systemic arterial $(\overline{A P})$, pulmonary arterial $(\bar{P} \overline{A P})$, and right atrial $(\overline{R A P})$ mean pressures and on cardiac index $(C I)$, stroke volume index (SVI), stroke work index (SWI), and systemic vascular resistance (SVR). Control values before prazosin (C1) and before hydralazine (C2) were not different. Compared with controls, changes in systemic and pulmonary arterial pressures were similar with the two drugs. However, the mean increase in cardiac index and the decrease in systemic vascular resistance with hydralazine were significantly greater than with prazosin. Haemodynamic changes after 3, 4, or $5 \mathrm{mg}$ prazosin were of similar magnitude.

P3, P4, P5 = prazosin 3, 4, and $5 \mathrm{mg}$; HD50, HD75 = hydralazine, 50 and $75 \mathrm{mg}$. 
dose. However, at the time of maximal increase in cardiac output, other haemodynamic changes were also observed. The haemodynamic changes after 3,4 , and $5 \mathrm{mg}$ doses of oral prazosin are summarised in the Table and in Fig 1a and 1b. Heart rate did not change significantly in any patient during prazosin treatment. There were slight but statistically significant decreases in pulmonary artery wedge, right atrial, mean pulmonary arterial, and mean systemic arterial pressures. There was a significant increase in cardiac index along with a decrease in systemic vascular resistance. Stroke volume and stroke work indices increased in most patients, though the increase in stroke work index was not statistically significant. An increase in stroke volume index, accompanying a decrease in pulmonary artery wedge pressure, suggested improved left ventricular performance. Haemodynamic changes were usually observed after the initial dose of 2 to $3 \mathrm{mg}$ oral prazosin. There were no further changes when the dose was increased to 4 or $5 \mathrm{mg}$. In an attempt to increase the response, two patients received a $20 \mathrm{mg}$ dose of prazosin without further increment in cardiac output or reduction in systemic vascular resistance.

\section{HAEMODYNAMIC EFFECTS OF ORAL \\ HYDRALAZINE}

In the same patients, the maximum haemodynamic response in terms of increase in cardiac output was also observed at one to two hours after administration of oral hydralazine. Haemodynamic changes after hydralazine in doses of $50 \mathrm{mg}$ and $75 \mathrm{mg}$ are summarised in the Table and in Fig. 1a and $1 b$. After $75 \mathrm{mg}$ hydralazine, there was no significant change in heart rate. There were slight, but statistically significant falls in pulmonary and systemic arterial and pulmonary artery wedge pressures. Right atrial pressure was unchanged. A small decrease in pulmonary vascular resistance was noted. There was a large increase in cardiac index (average $58 \%$ ) and a significant decrease in systemic vascular resistance. Stroke volume and stroke work indices increased greatly in most patients. Cardiac index, systemic vascular resistance, and stroke volume index after $50 \mathrm{mg}$ hydralazine were intermediate, being significantly different from control measurements, though the changes were less than those seen at the $75 \mathrm{mg}$ dose level. During continued administration of $75 \mathrm{mg}$ hydralazine, the haemodynamic changes were persistent.

COMPARISON BETWEEN HAEMODYNAMIC EFFECTS OF PRAZOSIN AND HYDRALAZINE (FIG. 2)

There was a significant difference between the

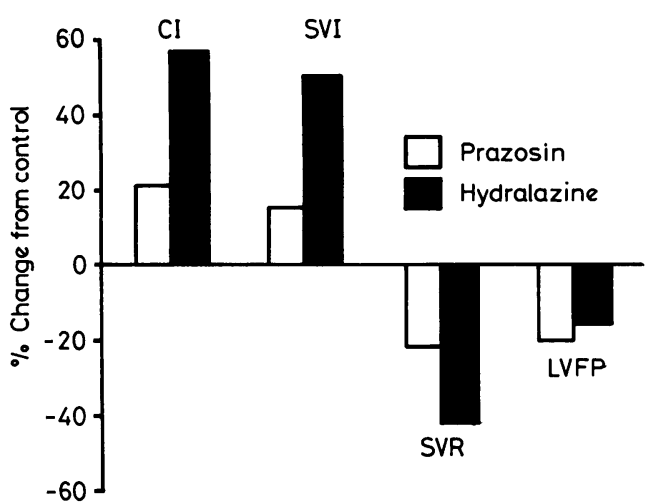

Fig. 2 Comparison between the haemodynamic effects of prazosin (5 $\mathrm{mg}$ ) and hydralazine (75 $\mathrm{mg}$ ) in patients with chronic heart failure. The magnitude of the decrease in left ventricular filling pressure (LVFP) was similar with both drugs. However, the increase in cardiac index (CI) and stroke volume index (SVI) and the decrease in systemic vascular resistance (SVR) were greater with hydralazine than with prazosin. The differences between the changes in CI, SVI, and $S V R$ were statistically significant, whereas the difference between the changes in LVFP were not.

maximal effects of prazosin (5 mg) and hydralazine (75 mg) on cardiac output and systemic vascular resistance. The average increase in cardiac output during prazosin treatment was 25 per cent. By contrast, hydralazine increased cardiac output by 58 per cent $(P<0.001)$. The decrease in calculated systemic vascular resistance during prazosin treatment $(-20 \%)$ was significantly less than that produced by hydralazine $(-40 \%)$. The increase in stroke work and stroke volume indices was also significantly greater with hydralazine than with prazosin. The small decreases in pulmonary artery wedge pressure with prazosin $(-21 \%)$ and with hydralazine $(-20 \%)$ were, however, similar. There was no significant change in heart rate with either drug. The decrease in systemic arterial mean pressure was small $(-8 \mathrm{mmHg})$ with both drugs. Postural hypotension and other untoward side effects did not occur with either drug during the period of administration.

On the other hand, there were no significant differences between the haemodynamic changes after prazosin and those after the lower dose of hydralazine $(50 \mathrm{mg})$.

\section{Discussion}

Beneficial haemodynamic effects of various nonparenteral vasodilator drugs in patients with chronic congestive heart failure have been documented in previous investigations. The most widely used non- 
parenteral vasodilators until recently have been the nitrates which, with adequate doses, decrease pulmonary and systemic venous pressures significantly in most patients (Franciosa et al., 1974b; Kovick et al., 1976). Though in some patients cardiac output increases, in the majority there is little or no change with the use of nitrates (Mantle et al., 1976; Chatterjee and Parmley, 1977). Since the major haemodynamic objectives of treatment of heart failure are to improve cardiac output and decrease systemic and pulmonary venous pressures, the search continues for more effective vasodilator drugs which can be used either alone or in combination (Awan et al., 1977; Parmley and Chatterjee, 1976). Recently, the haemodynamic effects of the two antihypertensive agents, hydralazine (Chatterjee et al., 1976b; Franciosa et al., 1977) and prazosin (Awan et al., 1977; Miller et al., 1977) have been investigated in patients with chronic congestive heart failure and a beneficial response to both drugs has been documented.

The present study confirms the beneficial haemodynamic effects of both vasodilator agents in patients with chronic congestive heart failure. Thus, with prazosin, there was usually an increase in cardiac output together with some decrease in pulmonary artery wedge pressure, suggesting improved left ventricular performance. However, there appears to be a significant difference between the haemodynamic response to prazosin observed in the present study and that reported by Miller et al. (1977) and by Awan et al. (1977) who observed a distinct decrease in pulmonary artery wedge pressure $(-45 \%)$, as compared with the present study $(-21 \%)$. The average increase in cardiac output in the present study $(+23 \%)$ was also appreciably less than that $(+48 \%)$ reported by Awan et al. (1977). These discrepancies were not the result of inadequate doses of prazosin; the cumulative dose in our study ranged up to $25 \mathrm{mg}$, which was more than in previous studies. Furthermore, the haemodynamic response was no better with increasing doses of prazosin. In our patients, the beneficial haemodynamic response was usually observed with the initial $3 \mathrm{mg}$ dose of oral prazosin. There was no further significant change when the dose was increased (Fig. 1a and b). Furthermore, preliminary investigations in our laboratory suggest a poor correlation between the haemodynamic effects of prazosin and its blood level (Arnold et al., 1979).

Differences in patient population may explain some of the differences observed in the response to prazosin. In the present study, almost all of our patients with chronic congestive heart failure were normotensive at the time of the investigation and the decrease in systemic arterial pressure was only slight, even with larger doses of prazosin. In the patients investigated by Miller et al. (1977) and Awan et al. (1977), the mean arterial pressure was considerably higher and the decrease in arterial pressure was also considerably greater. Since there is a relation between changes in arterial pressure and changes in pulmonary artery wedge pressure (Franciosa et al., 1974a), a large fall in arterial pressure will be associated with a more pronounced fall in pulmonary artery wedge pressure, as was observed in the patients studied by Miller $e t$ al. (1977) and Awan et al. (1977). In our normotensive patients, the decrease in arterial pressure with prazosin was less, as was the decrease in pulmonary artery wedge pressure.

These results confirm our previous experience with oral hydralazine (Chatterjee et al., 1976b). There was a significant increase in cardiac output associated with a decrease in calculated systemic vascular resistance. Additionally, the haemodynamic effects were greater when the dose of hydralazine was raised from $50 \mathrm{mg}$ to $75 \mathrm{mg}$. There was only a slight decrease in systemic arterial pressure without any significant change in heart rate. In many patients, there was some decrease in pulmonary artery wedge pressure after oral hydralazine, but this decrease, however, was relatively small. Though in our previous study a consistent decrease in pulmonary artery wedge pressure was not observed (Chatterjee et al., 1976b), other investigators have reported a fall in wedge pressure after oral administration of hydralazine in patients with chronic heart failure (Franciosa et al., 1977). The difference in the degree of systolic unloading of the left ventricle in different patient populations with varying severity of depression of cardiac function may account, to some extent, for the variations in the haemodynamic findings. With more severe depression of cardiac function, a better 'unloading' effect is expected. In the present study, almost all patients had severe heart disease and advanced left ventricular failure.

This study was designed to investigate the comparative haemodynamic effects of prazosin and hydralazine in the same patients with chronic congestive heart failure. The doses of these drugs were chosen on the basis of those shown to produce beneficial haemodynamic responses in different patient populations (Chatterjee et al., 1976b); Awan et al., 1977). Comparison of haemodynamic effects of hydralazine and prazosin in the same patients indicates that, in the prescribed doses, hydralazine produced greater haemodynamic effects than prazosin. The average increase in cardiac output with hydralazine was +58 per cent compared with 
+25 per cent increase with prazosin, a highly significant difference $(P<0.001)$. The increase in stroke volume and stroke work indices was also significantly greater with hydralazine. The decrease in pulmonary artery wedge pressure was similar with hydralazine and prazosin. These findings indicate that, though both drugs improved left ventricular performance, improvement with hydralazine was greater than with prazosin (Fig. 3).

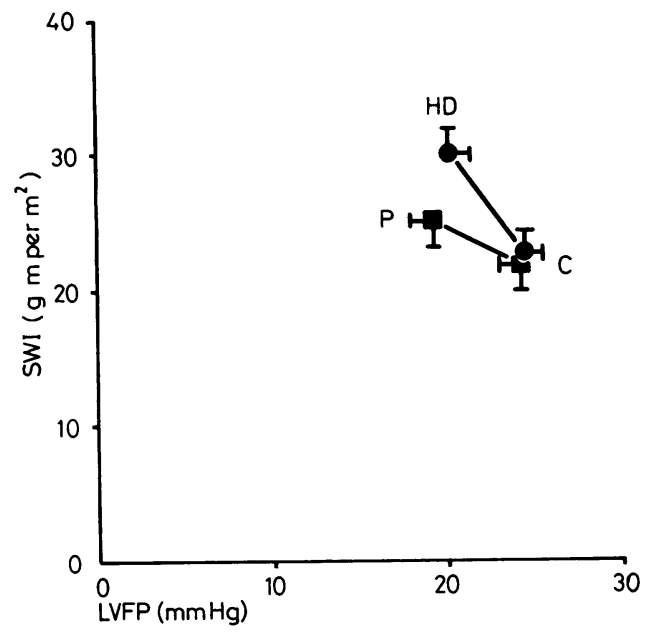

Fig. 3 The influence of oral hydralazine ( $75 \mathrm{mg}$ ) (HD) and oral prazosin (5 mg) (P) on left ventricular function in patients with chronic heart failure. There was a greater increase in stroke work index (SWI) with hydralazine than with prazosin. With prazosin left ventricular filling pressure ( $L V F P$ ) decreased to $19 \pm 2$ from control $(24 \pm 1 \mathrm{mmHg}$ ). With hydralazine, $L V F P$ decreased to $20 \pm 2 \mathrm{mmHg}$ from control $(24 \pm 1 \mathrm{mmHg})$. The difference between the decreases in LVFP with prazosin and hydralazine was not statistically significant.

Of the 11 patients in this study, eight received prazosin initially; though hydralazine was not given to these patients until the haemodynamic measurements had returned to control levels, the possibility exists that the altered circulatory state induced by prazosin was still present when hydralazine was administered, accounting for a greater increase in cardiac output with hydralazine. However, in three patients who received hydralazine first, a similar difference in the haemodynamic response between hydralazine and prazosin was observed. Furthermore, in previous studies, in which hydralazine was not preceded by prazosin, a similar haemodynamic response was observed (Chatterjee et al., 1976b). It seems unlikely, theretore, that a better haemodynamic response to hydralazine can be explained by a possible alteration in the circulatory state induced by previously administered prazosin.
In conclusion, the present study suggests that hydralazine may be more effective than prazosin in improving left ventricular performance in some patients with severe chronic congestive heart failure. However, the potential complications of long-term hydralazine treatment may be considerable. The lupus syndrome, pyridoxine deficiency polyneuropathy, fluid retention, and weight gain may preclude the use of hydralazine in some patients (Perry, 1973). In such circumstances, prazosin may be a reasonable alternative drug to consider.

\section{References}

Arnold, S., Williams, R., Ports, T., Baughman, R., Benet, L., and Chatterjee, K. (1979). Prazosin kinetics and effect in congestive heart failure (abstract). American fournal of Cardiology, 43, 403.

Awan, N. A., Miller, R. R., DeMaria, A. N., Maxwell, K. S., Neumann, A., and Mason, D. R. (1977). Efficacy of ambulatory systemic vasodilator therapy with oral prazosin in chronic refractory heart failure: concomitant relief of pulmonary congestion and elevation of pump output demonstrated by improvements in symptomatology, exercise tolerance, hemodynamics and echocardiography. Circulation, 56, 346-354.

Chatterjee, K., Drew, D., Parmley, W. W., Klausner, S. C., Polansky, J., and Zacherle, B. (1976a). Combination vasodilator therapy for severe chronic congestive heart failure. Annals of Internal Medicine, 85, 467-470.

Chatterjee, K., and Parmley, W. W. (1977). The role of vasodilator therapy in heart failure. Progress in Cardiovascular Diseases, 19, 301-325.

Chatterjee, K., Parmley, W. W., Massie, B., Greenberg, B., Werner, J., Klausner, S., and Norman, A. (1976b). Oral hydralazine therapy for chronic refractory heart failure. Circulation, 54, 879-883.

Forrester, J. S., Ganz, W., Diamond, G., McHugh, T., Chonette, D. W., and Swan, H. J. C. (1972). Thermodilution cardiac output determination with a single flow directed catheter. American Heart fournal, 83, 306-311.

Franciosa, J. A., Guiha, N. H., Limas, C. J., Paz, S., and Cohn, J. N. (1974a). Arterial pressure as a determinant of left ventricular filling pressure after acute myocardial infarction. American fournal of Cardiology, 34, 506-512.

Franciosa, J. A., Mikulic, E., Cohn, J. N., Jose, E., and Fabie, A. (1974b). Haemodynamic effects of orally administered isosorbide dinitrate in patients with congestive heart failure. Circulation, 50, 1020-1024.

Franciosa, J. A., Pierpont, G., and Cohn, J. N. (1977). Haemodynamic improvement after oral hydralazine in left ventricular failure. Annals of Internal Medicine, 86, 388-393.

Gold, H. K., Leinbach, R. C., and Sanders, C. A. (1972). Use of sublingual nitroglycerin in congestive failure following acute myocardial infarction. Circulation, 46, 839-845.

Gray, R., Chatterjee, K., Vyden, J. R., Ganz, W., Forrester, J. S., and Swan, H. J. C. (1975). Hemodynamic and metabolic effects of isosorbide dinitrate in chronic congestive heart failure. American Heart fournal, 90, 346-352.

Guiha, N. H., Cohn, J. N., Mikulic, E., Franciosa, J. A., and Limas, J. C. (1974). Treatment of refractory heart failure with infusion of nitroprusside. New England fournal of Medicine, 291, 587-592.

Kovick, R. B., Tillisch, J. H., Berens, S. C., Bramowitz, A. D., and Shine, K. I. (1976). Vasodilator therapy for chronic left ventricular failure. Circulation, 53, 322-328. 
Majid, P. A., Sharma, B., and Taylor, S. H. (1971). Phentolamine for vasodilator treatment of severe heart failure. Lancet, 2, 719-724.

Mantle, J. A., Russell, R. O., Moraski, R. E., and Rackley, C. E. (1976). Isosorbide dinitrate for the relief of severe heart failure after acute myocardial infarction. American fournal of Cardiology, 37, 263-268.

Miller, R. R., Awan, N. A., Maxwell, K. S., and Mason, D. R. (1977). Sustained reduction of cardiac impedance and preload in congestive heart failure with the antihypertensive vasodilator prazosin. New England fournal of Medicine, 298, 303-307.

Parmley, W. W., and Chatterjee, K. (1976). Vasodilator therapy for chronic heart failure. Cardiovascular Medicine, 1, 17-23.
Perry, H. M. (1973). Late toxicity to hydralazine resembling systemic lupus erythematosus or rheumatoid arthritis. American fournal of Medicine, 54, 58-72.

Taylor, W. R., Forrester, J. S., Magnusson, P., Takano, T., Chatterjee, K., and Swan, H. J. C. (1976). The hemodynamic effects of nitroglycerin ointment in congestive heart failure. American fournal of Cardiology, 38, 469-473.

Requests for reprints to Professor Kanu Chatterjee, Department of Medicine, Room 1186 Moffitt Hospital, University of California, San Francisco, California 94143, USA. 